\title{
Lewis Acid Facilitate Deep Eutectic Solvent (DES) Pretreatment for Producing the High-Purity and Antioxidative Lignin
}

Zhi-Kun Wang, ${ }^{\dagger}$ Si Hong, ${ }^{\ddagger}$ Jia-long Wen,,${ }^{\ddagger}$ Cheng-Ye Ma,${ }^{\ddagger}$ Lv Tang,${ }^{\dagger}$ Hao Jiang, ${ }^{\dagger}$ Jun-Jie Chen,${ }^{\dagger}$ Sha Li, ${ }^{\dagger}$ Xiao-Jun Shen, ${ }^{*}, \uparrow,, \|$ Tong-Qi Yuan

Zhejiang Provincial Key Laboratory of Chemical Utilization of Forestry Biomass, Lin'an, Zhejiang 311300, (P. R. China).

*Beijing Key Laboratory of Lignocellulosic Chemistry, Beijing Forestry University, No. 35 Tsinghua East Road, Haidian District, Beijing 100083, China.

$\S$ Beijing National Laboratory for Molecular Sciences, CAS Key Laboratory of Colloid and Interface and Thermodynamics, CAS Research/Education Center for Excellence in Molecular Sciences, Institute of Chemistry, Chinese Academy of Sciences, Beijing 100190 (P. R. China). "School of Chemistry and Chemical Engineering, University of Chinese Academy of Sciences, Beijing 100049 (P. R. China).

*Corresponding authors. shenxiaojun@iccas.ac.cn.

Number of pages: 5

Number of Tables: 1

Number of Figures: 2 


\section{Preparation of double enzymatic mild lignin (DEL)}

To maximize remove the carbohydrates from Hybrid Pennisetum sawdust and remain lignin as residual lignin, Hybrid Pennisetum was undergone ball-milling and excessive amounts cellulase (50 FPU/g substrates) hydrolysis. The ball-milling process was performed in a planetary ball mill (FritschGMBH, Idar-Oberstein, Germany) for $6 \mathrm{~h}$. Hybrid Pennisetum was milled at a time after dried at $60 \mathrm{oC}$ in an oven for overnight. The ball-milled Hybrid Pennisetum (10g) was suspended in acetate buffer $(0.05 \mathrm{mM}, 250 \mathrm{ml}, \mathrm{pH} 4.8)$ with loading of $5.0 \mathrm{~mL}$ of Novozyme Celluclast (500 FPU). The reaction mixture was incubated at $50 \mathrm{oC}$ in a rotary shaker $(150 \mathrm{rpm})$ for $72 \mathrm{~h}$. After enzymatic hydrolysis, the mixture was centrifuged and the residue lignin was washed extensively with hot acid water, and then freeze-dried. The dried residue lignin was undergone ball-milling again and cellulase hydrolysis under same condition. 

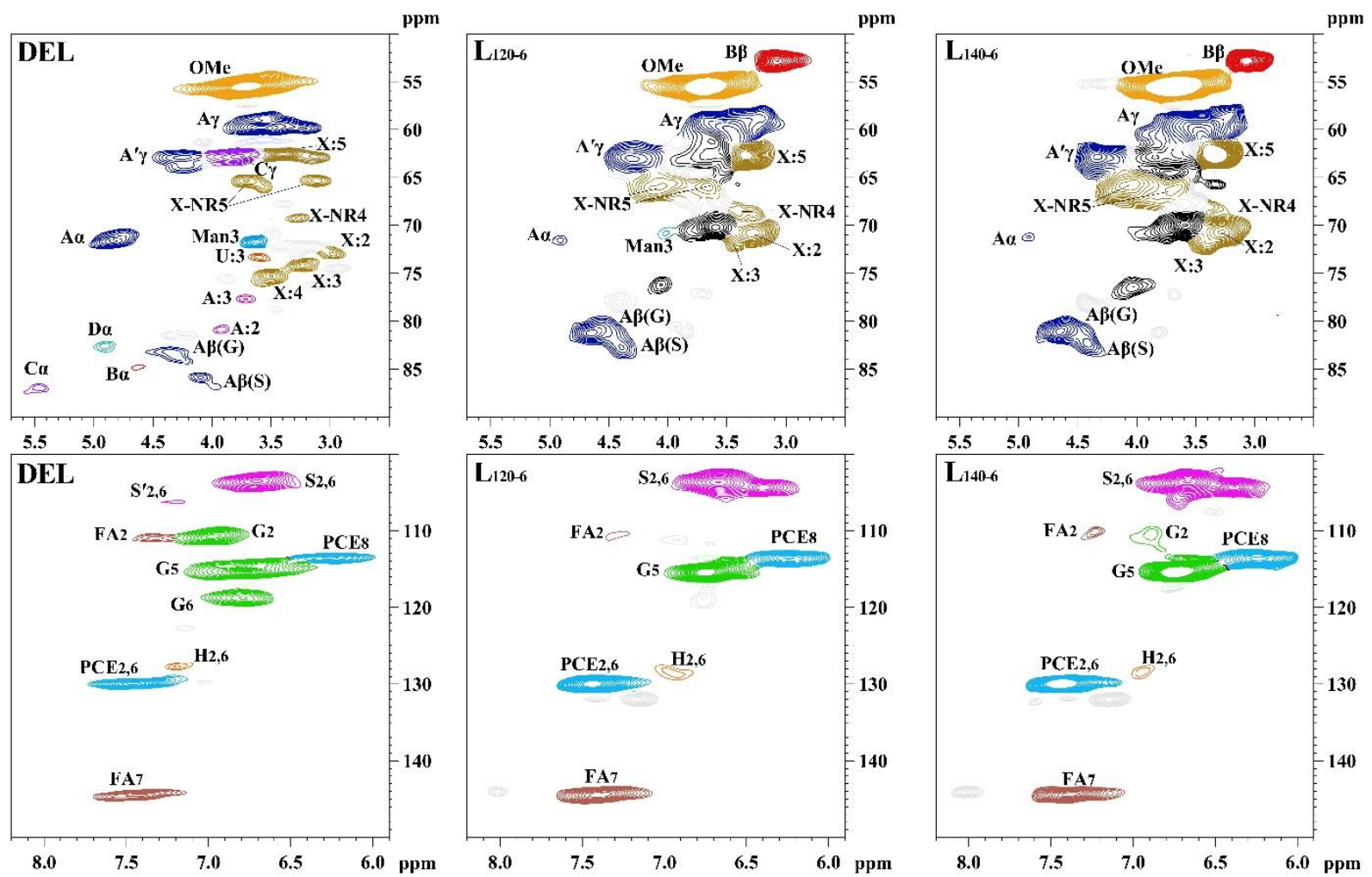

Figure S1 Side-chain regions and aromatic regions in the 2D-HSQC spectra of the DELs and the regenerated lignin by different temperatures. 

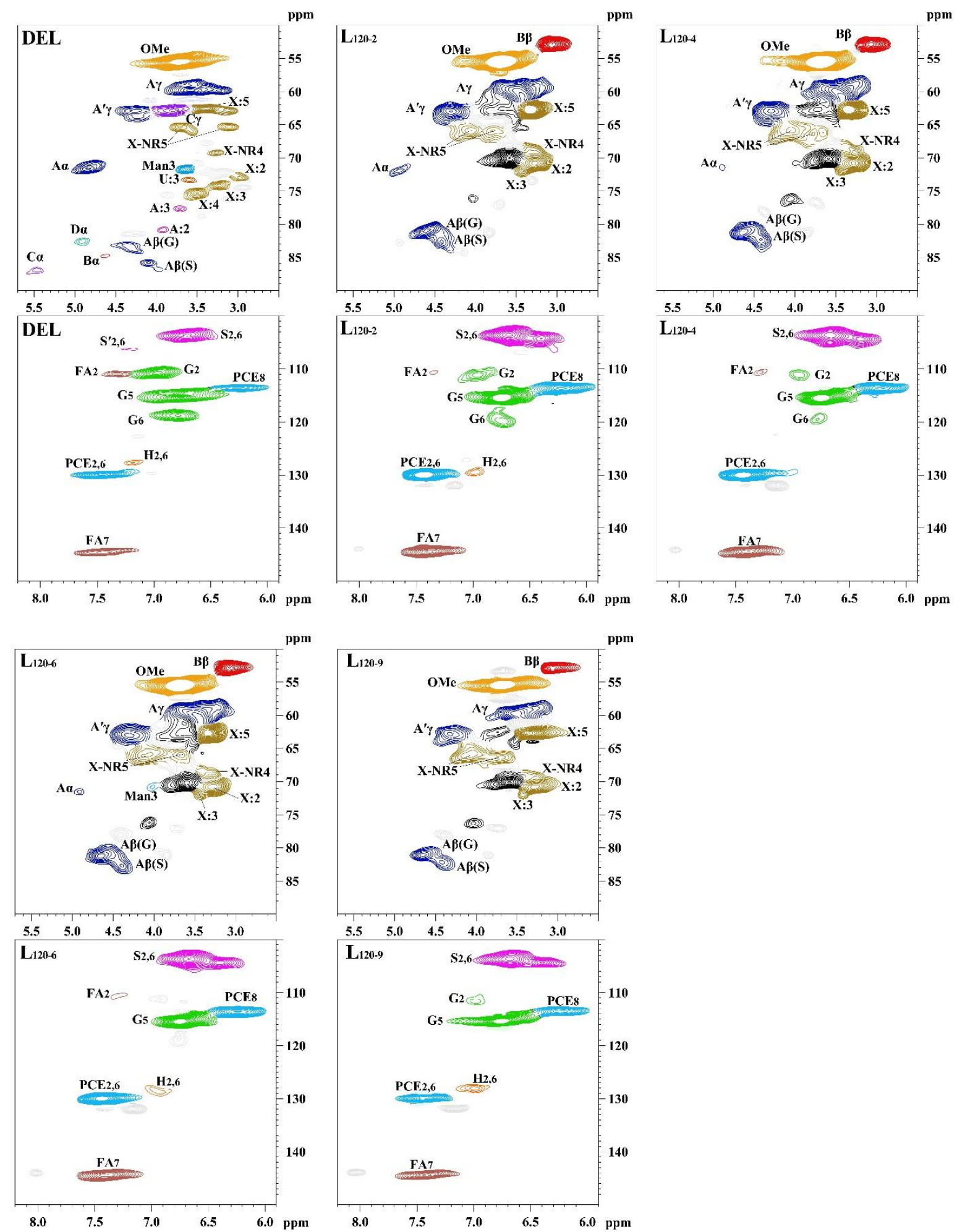

Figure S2 Side-chain regions and aromatic regions in the 2D-HSQC spectra of the DELs and the regenerated lignin by different time. 
Table S1. Assignments of main ${ }^{13} \mathrm{C}-{ }^{1} \mathrm{H}$ cross-signals in the HSQC spectra of DELs.

\begin{tabular}{|c|c|c|}
\hline Lable & $\delta_{\mathrm{C}} / \delta_{\mathrm{H}}(\mathrm{ppm})$ & Assignments \\
\hline $\mathrm{C}_{\beta}$ & $52.9 / 3.45$ & $\mathrm{C}_{\beta}-\mathrm{H}_{\beta}$ in phenylcoumaran substructures $(\mathrm{C})$ \\
\hline$-\mathrm{OCH}_{3}$ & $55.5 / 3.70$ & $\mathrm{C}-\mathrm{H}$ in methoxyls \\
\hline $\mathrm{A}_{\gamma}$ & $59.8 / 3.58$ & $\mathrm{C}_{\gamma}-\mathrm{H}_{\gamma}$ in $\beta-O-4^{\prime}$ substructures (A) \\
\hline $\mathrm{F}_{\gamma}$ & $61.4 / 4.08$ & $\mathrm{C}_{\gamma}-\mathrm{H}_{\gamma}$ in $p$-hydroxycinnamyl alcohol end groups $(\mathrm{F})$ \\
\hline $\mathrm{A}_{\gamma}^{\prime}$ & $63.0 / 4.26$ & $\mathrm{C}_{\gamma}-\mathrm{H}_{\gamma}$ in $\gamma$-acylated $\beta-O-4^{\prime}$ substructures $\left(\mathrm{A}^{\prime}\right)$ \\
\hline $\mathrm{C}_{\gamma}$ & $62.7 / 3.80$ & $\mathrm{C}_{\gamma}-\mathrm{H}_{\gamma}$ in phenylcoumaran substructures $(\mathrm{C})$ \\
\hline $\mathrm{B}_{\gamma}$ & $70.9 / 3.80-4.18$ & $\mathrm{C}_{\gamma}-\mathrm{H}_{\gamma}$ in $\beta-\beta^{\prime}$ resinol substructures (B) \\
\hline $\mathrm{A}_{\alpha}$ & $71.6 / 4.84$ & $\mathrm{C}_{\alpha}-\mathrm{H}_{\alpha}$ in $\beta-O-4^{\prime}$ units (A) \\
\hline $\mathrm{D}$ & $82.6 / 4.90$ & $\mathrm{C}_{\alpha}-\mathrm{H}_{\alpha}$ in benzyl ether LCC structures \\
\hline $\mathrm{A}_{\beta(\mathrm{G} / \mathrm{H})}$ & $83.5 / 4.33$ & $\mathrm{C}_{\beta}-\mathrm{H}_{\beta}$ in $\beta-O-4^{\prime}$ substructures linked to $\mathrm{G} / \mathrm{H}$ units $(\mathrm{A})$ \\
\hline $\mathrm{B}_{\alpha}$ & $84.7 / 4.64$ & $\mathrm{C}_{\alpha}-\mathrm{H}_{\alpha}$ in $\beta-\beta^{\prime}$ resinol substructures (B) \\
\hline $\mathrm{A}_{\beta(\mathrm{S})}$ & $85.9 / 4.10$ & $\mathrm{C}_{\beta}-\mathrm{H}_{\beta}$ in $\beta-O-4^{\prime}$ substructures linked to $\mathrm{S}$ units (A) \\
\hline $\mathrm{C}_{\alpha}$ & $86.8 / 5.45$ & $\mathrm{C}_{\alpha}-\mathrm{H}_{\alpha}$ in phenylcoumaran substructures $(\mathrm{C})$ \\
\hline $\mathrm{S}_{2,6}$ & $103.6 / 6.72$ & $\mathrm{C}_{2,6}-\mathrm{H}_{2,6}$ in syringyl units $(\mathrm{S})$ \\
\hline $\mathrm{S}_{2,6}^{\prime}$ & $106.2 / 7.23$ & $\mathrm{C}_{2,6}-\mathrm{H}_{2,6}$ in oxidized $\left(\mathrm{C}_{\alpha}=\mathrm{O}\right)$ syringyl units $\left(\mathrm{S}^{\prime}\right)$ \\
\hline $\mathrm{G}_{2}$ & $110.7 / 6.96$ & $\mathrm{C}_{2}-\mathrm{H}_{2}$ in guaiacyl units $(\mathrm{G})$ \\
\hline $\mathrm{G}_{5}$ & $114.5 / 6.69$ & $\mathrm{C}_{5}-\mathrm{H}_{5}$ in guaiacyl units $(\mathrm{G})$ \\
\hline $\mathrm{G}_{6}$ & $118.8 / 6.78$ & $\mathrm{C}_{6}-\mathrm{H}_{6}$ in guaiacyl units $(\mathrm{G})$ \\
\hline $\mathrm{H}_{2,6}$ & $127.6 / 7.19$ & $\mathrm{C}_{2,6}-\mathrm{H}_{2,6}$ in $\mathrm{H}$ units $(\mathrm{H})$ \\
\hline $\mathrm{PCE}_{3,5}$ & $115.5 / 6.76$ & $\mathrm{C}_{3,5}-\mathrm{H}_{3,5}$ in $p$-coumarate $(\mathrm{PCE})$ \\
\hline $\mathrm{PCE}_{2,6}$ & $130.0 / 7.46$ & $\mathrm{C}_{2,6}-\mathrm{H}_{2,6}$ in $p$-coumarate (PCE) \\
\hline $\mathrm{PCE}_{7}$ & $144.7 / 7.50$ & $\mathrm{C}_{7}-\mathrm{H}_{7}$ in $p$-coumarate (PCE) \\
\hline $\mathrm{PCE}_{8}$ & $113.6 / 6.27$ & $\mathrm{C}_{8}-\mathrm{H}_{8}$ in $p$-coumarate $(\mathrm{PCE})$ \\
\hline $\mathrm{FA}_{2}$ & $110.9 / 7.35$ & $\mathrm{C}_{2}-\mathrm{H}_{2}$ in ferulate (FA) \\
\hline $\mathrm{FA}_{6}$ & $122.9 / 7.13$ & $\mathrm{C}_{6}-\mathrm{H}_{6}$ in ferulate $(\mathrm{FA})$ \\
\hline $\mathrm{FA}_{7}$ & $144.7 / 7.50$ & $\mathrm{C}_{7}-\mathrm{H}_{7}$ in ferulate $(\mathrm{FA})$ \\
\hline
\end{tabular}

